\title{
Neuropsychological Profiles of Three Subtypes of Impulsivity in the General Population: A Young Adults Study
}

\author{
Perfil neuropsicológico en tres subtipos de impulsividad en población argentina
}

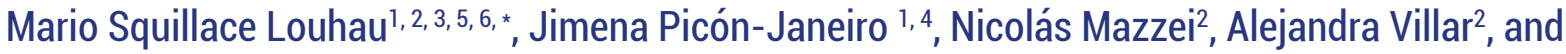
Susana Azzollini'1, 4,5

\begin{abstract}
The impulsivity construct has been investigated in the psychological literature as both a personality factor and a manifestation of the cognitive functioning of individuals. In addition, an increasing number of studies have shown that impulsivity is not a unitary concept and that it must be conceived of as several subtypes. We investigated whether a self-report test of three types of impulsivity could be a good predictor of cognitive functioning in healthy individuals. The sample was composed of 230 subjects ( $65 \%$ women) with a mean age of 28.4 years (SD $=13.6$ years) from the general population of the Autonomous City of Buenos Aires, Argentina. The sample was evaluated using the Questionnaire on Compulsive Urgency, Sensation Seeking, and Impulsive Improvidence (CUBI-18; Squillace Louhau, \& Picón Janerio, 2019), which measures three impulsivity subtypes. A battery of neuropsychological tests was administered to measure not only executive-attentional functioning, verbal and non-verbal fluency, and speed of processing, but also strategies in the decision-making process. The results showed a differential profile of the three subtypes of impulsivity. Compulsive Urgency was associated with greater executive- attentional difficulties, Impulsive Improvidence with lower fluency in processing nonverbal information, and Sensation Seeking with better general cognitive performance and risk-taking during decision-making.
\end{abstract}

\section{Resumen}

El constructo impulsividad ha sido investigado, dentro de la literatura psicológica, tanto como un factor de personalidad como una manifestación del funcionamiento cognitivo de los individuos. A su vez, la creciente investigación muestra que ésta no debe concebirse como un concepto unitario sino ser definida a través de varios subtipos. En este trabajo se buscó indagar sobre la posibilidad de que una prueba de auto-informe de tres tipos de impulsividad sea un buen predictor del funcionamiento cognitivo en individuos sanos. La muestra estuvo constituida por 230 sujetos ( $65 \%$ mujeres) con edad media de 28.4 años ( $S D=13.6$ años) de la población general de la Ciudad Autónoma de Buenos Aires, Argentina. Se evaluó a través del Cuestionario de Urgencia Compulsiva, Búsqueda de Sensaciones e Impulsividad por Imprevisión (CUBI, Squillace Louhau, \& Picón Janerio, 2019) que mide los tres subtipos de impulsividad. En relación a esto, se utilizó una batería de pruebas neuropsicológicas para mensurar tanto el funcionamiento ejecutivo-atencional, la fluencia verbal y no verbal, la velocidad de procesamiento, así como las estrategias en el proceso de toma de decisiones. Los resultados encontrados han sido significativos y han demostrado un perfil diferencial de los tres subtipos de impulsividad. Primero, la Urgencia Compulsiva puede relacionarse con mayores dificultades ejecutivo-atencionales, segundo, la Impulsividad por Imprevisión con una menor fluencia del procesamiento de información no verbal y, por último, la Búsqueda de Sensaciones con un mejor rendimiento cognitivo general y la toma de riesgos durante la toma de decisiones. En conclusión, la prueba de auto-informe de tres tipos de impulsividad mencionada puede ser un buen predictor del funcionamiento cognitivo en contextos no patológicos.

Keywords:

Compulsive Urgency, Impulsive Improvidence, Sensation Seeking, CUBI.

Palabras Claves:

Urgencia Compulsiva, Impulsividad por Imprevisión, Búsqueda de Sensaciones, CUBI.

1. Universidad de Buenos Aires, Argentina.

2. Instituto de Investigación de la Universidad del Salvador, Argentina.

3. Pontificia Universidad Católica Argentina.

4. Consejo Nacional de Investigaciones Científicas y Técnicas, Argentina.

5. Universidad de la Defensa Nacional, FE, Centro de Investigaciones Sociales y Humanas para la Defensa, Argentina.

6. Hospital Universitario Austral, Argentina.

* Corresponding author: msquillace@psi.uba.ar

Manuscript received 20-06-2018; revised 22-09-2018; accepted 14-11-2018. 


\section{Introduction}

For several decades, literature has posited that impulsivity is associated with neuropsychological alterations of both behavioural and cognitive inhibition (Billieux, Gay, Rochat, \& Van der Linden, 2010; López, Dauvilliers, Jaussent, Billieux, \& Bayard, 2015; Wilbertz et al., 2014), psychopathological disorders (Berg, Latzman, Bliwise, \& Lilienfeld, 2015; Ray, Poythress, Weir, \& Rickelm, 2009), addictive behaviours (Billieux, Rochat, Rebetez, \& Van der Linden, 2008; Billieux, Van der Linden, \& Ceschi, 2007), as well as risk-taking and pathological gambling (Cyders \& Smith, 2008; Stanford, Mathias, Dougherty, Lake, Anderson, \& Patton, 2009). However, impulsivity has been described in very different ways by a diversity of studies. Thus, many reports dealing with this construct do not fit for equivalence, so the different descriptions and results cannot be compared (Rochat, Billieux, Gagnon, \& Van der Linden, 2018; Squillace, Picón Janeiro, \& Schmidt, 2011). Therefore, some authors have tried to elucidate how many subtypes of impulsivity must be taken into account to fully understand this psychological construct. An enlightening approach is that of Whiteside and Lynam (2001), who divide the concept into four dimensions, based on the theory of the five great personality factors (NEO-PIR; Costa Jr \& McCrae, 1995). These authors identified urgency, sensation seeking, lack of premeditation, and lack of perseverance as variants of what is called impulsivity. These four subtypes make it possible to identify the different ideas researchers have associated with this construct. To summarize, urgency is related to difficulty in self-regulatiing impulses (compulsion), which occurs under stress situations or conditions of negative affect; sensation is the tendency to seek and respond to signal stimuli that are predictors of excitement or novelty; lack of premeditation refers to the inability to foresee the consequences of one's own behaviour and to act thoughtlessly; and finally, lack of perseverance is defined by the tendency to abandon tasks when they do not provide immediate reinforcements or when boredom ensues.

This theoretical perspective led to the construction of the Urgency, Lack of Premeditation, Lack of Perseverance, and Sensation Seeking questionnaire (UPPS; Whiteside \& Lynam, 2001; Whiteside, Lynam, Miller, \& Reynolds, 2005). Additionally, Cyders and Smith (2007) adapted the multifaceted study on impulsivity by including the distinction between positive and negative urgency to construct a diagnostic interview. However, the factor analysis resulting from the new instrument of five concepts showed that the best solution was a model based on three large dimensions. The first dimension was called urgency, and it included the positive and negative aspects of urgency as two facets of the same dimension; the second dimension, called consciousness deficit, included the lack of premeditation and lack of perseverance facet; and the third dimension of the model was sensation seeking. These findings are similar to those found by Squillace and Picón-Janeiro (2017) when they constructed an instrument to measure impulsivity in the Argentine population. From 12 scales that measured different concepts of impulsivity, they concluded that the best factorial structure was one of three factors, called compulsive urgency, impulsive improvidence, and sensation seeking.

Taking this division of impulsivity in subtypes into account, the confirmation of whether these concepts were good predictors of individual behaviour had to be explored. For that matter, several recent investigations of diverse topics such as decision making, positive and negative emotions and mood states, substance and non-substance abuse, attentional interference and posttraumatic stress attempt to enumerate such a complex neuropsychological phenomenon.

To begin with, Bayard, Raffard, and Gely-Nargeot (2011) indicated that some facets of UPPS predict risky decision-making. Their study evaluated the decisionmaking process in healthy participants, using two types of experimental tasks: the Iowa Gambling Task (IGT) and the Game of Dice Task (GDT). These instruments enable the testing of the amount of risky and safe choices participants make and how their choices affect their acquisition and loss of fake money. Urgency and sensation seeking predicted a greater number of risky choices in the GDT (controlling for age and sex effects). The other two UPPS aspects, on the other hand, were not related to risk-taking.

Furthermore, when the aspects of impulsivity were investigated in Neuropsychological profiles for general population, not all subtypes were found to be related to cognitive profiles of interviewees in the same way. Gay, Rochat, Billieux, d'Acremont and Van der Linden (2008) found that, in a school population, only urgency predicted the performance of neuropsychological tasks. Thus, individuals with a higher level of urgency traits committed more commission errors in go/no-go tasks. The effects were preserved even controlling for the influence of the other facets of impulsivity, age, and education level. The authors related the urgency trait with an inadequate inhibition of high-handed response.

Another study found a difference in the cognitive profile of individuals with greater lack of perseverance and urgency (Gay et al., 2010). According to these authors, people with high urgency suffer from the interference of elements in the environment they are not intentionally paying attention to; in other words, distractors interfere with their performance. On the other hand, those who lack perseverance are subject to interference by their own thought processes. This 
interference from internal thoughts hampers the working memory of individuals who deliberately pay attention to these thoughts amd lose track of the objective of the task in progress.

In addition to different neuropsychological phenomena related to risk-taking and impulsivity, Herman, Critchley and Duka (2018) linked also mood states and interoception with consequences of impulsive decisions and actions by examining how personality traits of behavioural tendencies, interoceptive sensibility and transient mood states can predict behavioural performance on impulsivity and risk-taking tasks. They observed a clear separation of measures, traits and behaviours where sensation seeking, reward sensitivity and probability discounting reflected risktaking, separated from measures associated with impulsivity. The most significant finding is related to emotional states: positive affect was associated with increased risk-taking tendencies and risky decisionmaking while negative emotions were related to heightened impulsivity measures. Lastly, interoceptive sensibility was only associated with negative emotions. These findings support the idea that risk-taking and impulsivity represent distinct constructs affected differentially by current mood states.

Cyders and Coskunpinar (2011) designed a study to observe the overlap between self-reports of impulsivity and laboratory experiments designed to measure the construct. To this end, they conducted a meta-analysis of 27 publications based on the multifaceted conceptualization of the impulsivity of Whiteside and Lynam (2001). The authors detected that despite significant relations, the overlap effects were small. It is interesting to note, however, that the four aspects were related to different characteristics of behaviour inhibition. Lack of premeditation was found to be associated with difficulty in inhibiting highhanded response, ability to postpone responses, and distortions in time measurement. Urgency was related to difficulty in inhibiting high-handed response, and lastly, sensation seeking was associated with the ability to postpone the response performance.

With regard to post-traumatic stress disorder and impulsivity, investigators revealed that the negative urgency facet of impulsivity was the most predictive, as it was best associated with all of this disorder's symptom clusters. In this sense, sensation seeking did not predict post-traumatic stress disorder's intrusion symptoms, but did predict the other symptom clusters of post-traumatic stress disorder. Lack of perseverance only predicted intrusion symptoms, while lack of premeditation only predicted post-traumatic stress disorder's mood and/or cognition symptoms. (Roley, Contractor, Weiss, Armour, \& Elhai, 2017).

Rochat et al. (2018) reviewed several studies using the UPPS model and concluded that the different facets of impulsivity have specific underlying neural substrates and mechanisms. Urgency was produced by deficiencies in the inhibition of internal high-handed response, giving rise to characteristic manifestations of this personality trait. These deficits may be shown by means of go/no go type tests. Urgency-related manifestations depend on the functioning of orbitofrontal circuits regarding the ventromedial prefrontal cortex as well as the right inferior frontal gyrus, the anterior cingulate, and the amygdala. Lack of premeditation was linked to risk-taking due to lack of anticipation of actions consequences during the decision-making process. According to the authors, tests like IGT reveal the behaviour of individuals who lack premeditation. Regions such as the insula, amygdala, dorsolateral and prefrontal cortices may be involved in the manifestation of this characteristic. Lack of perseverance is linked to the difficulty in resisting proactive interference, that is, the difficulty in preventing memories from interfering with maintenance of the behavioural goal. The left lateral and anterior prefrontal cortices would also be involved. Finally, sensation seeking is caused by high sensitivity to reward signals that links individuals to the creation of powerful appetitive learning. Reinforcement learning paradigms reveal the behaviours of this trait. To conclude, it is estimated that prefrontal regions such as the posterior medial orbitofrontal cortex, basal ganglia, and insula underlie this sensitivity to learning reward signals.

Finally, Rømer Thomsen et al. (2018) also used the UPPS model to investigate the role that impulsivity plays not only in substance abuse and gambling disorder but also on other non-substance addiction-related behaviours. In this respect, in addition to administering the questionnaire regarding problematic substance use (alcohol, cannabis and other drugs) participants completed the UPPS-P Questionnaire in reference to non-substance data as Internet gaming, pornography and food. As the outcome of this study indicated, the UPPS-P model was positively associated with indicators of all addiction-related behaviours except problematic internet gaming; sensation seeking and lack of perseverance were associated with problematic use of alcohol, urgency with problematic use of cannabis, and lack of perseverance with problematic use of noncannabis drugs. Furthermore, urgency and lack of perseverance were associated with binge eating and lack of perseverance was associated with problematic use of pornography. As can be seen above, the role of trait impulsivity can be observed across multiple addiction-related behaviours and as this study shows, urgency and lack of perseverance in youth can be considered as potential predictors for the development of addictions and as potential preventative therapeutic targets. Finally, even though this article doesn't focus on treatment of impulsivity disorders, it is necessary 
to mention the importance of subdividing the different types to achieve a better outcome in the clinical field. To this point, refer to the recent paper Recommendations for applying a multi-dimensional model of impulsive personality to diagnosis and treatment (Um, Hershberger, Whitt, \& Cyders, 2018).

In summation, recent studies reveal different subtypes of impulsivity as well as specific underlying neural substrates and mechanisms.

\section{Objectives}

In this work, we investigated whether each subtype of impulsivity was differentially related to neuropsychological deficits. We also aimed to discover which of the facets served as good predictors of strategy in decision-making. We therefore observed whether the discrimination between subtypes contributed to precision in detecting the cognitive and behavioural profile of the interviewee. We were also interested in identifying whether these phenomena, clearly distinguished in the pathological population, were also found more subtly in the general population. Nevertheless, the lack of perseverance was not included. We considered it to be a characteristic associated with lack of premeditation rather than a subtype of impulsivity (Cyders \& Smith, 2007). A common feature of urgency, sensation seeking, and lack of premeditation is quick and urgent action, which lack of perseverance does not include.

Taking into account this tripartite classification of impulsivity - urgency, sensation seeking and lack of premeditation -, the Compulsive Urgency, Sensation Seeking, and Impulsive Improvidence Questionnaire (CUBI-18, Squillace Louhau \& Picón Janerio, 2019) was constructed in advance. We selected this instrument to measure impulsivity in this study.

\section{Subjects}

The sample consisted of 230 subjects (65\% women) from the general population of the Autonomous City of Buenos Aires, Argentina. The mean age was 28.4 years (SD $=13.6$ years), the minimum age being 18 and the maximum 63 . The participants' educational level was distributed as follow: $1.7 \%$ elementary education, $40 \%$ secondary education, $53 \%$ university/tertiary education, and $5.2 \%$ graduate education. The subject's marital status was: $62.6 \%$ single, $23 \%$ married, $2.1 \%$ separated, and $12.3 \%$ in a relationship.

The inclusion criteria for the population sample excluded the following participants: psychologists and psychology students; patients taking psychiatric medication or diagnosed with psychopathological disordertomakesurethatthescoresinpsychopathological symptoms were subclinical; subjects with a history of seizures and/or repeated absences or diagnosed with epilepsy; individuals who had suffered from a coma, cerebrovascular accident, or cranial trauma with loss of consciousness or confusion longer than 30 minutes; subjects with uncompensated auditory or visual deficit, or who had been diagnosed with neurological disease, uncontrolled hypo- or hyperthyroidism, or chronic drug use. The criteria also required individuals to be in good condition to perform the task at the time of the encounters, excluding subjects with clear signs of fever, pain, depression, or anxiety.

In addition, participants signed an informed consent (based on the statements of the Helsinski World Medical Assembly), where the person responsible for the experiment committee maintained a strict respect for confidentiality and anonymity of the collected data.

\section{Instruments}

\section{Impulsivity measures}

In order to measure the three subtypes of impulsivity the Compulsive Urgency, Sensation Seeking, and Impulsive Improvidence Questionnaire (CUBI-18, Squillace Louhau \& Picón Janerio, 2019) was administered. This instrument consists of 18 items, six of which measure Impulsive Improvidence (II), six Sensation Seeking (SS) and the last six Compulsive Urgency (CU). It is a self-report questionnaire composed of statements about personality and the respondents must indicate to what extent the statements describe their habitual behaviour, using a five-point Likert scale: "totally agree," "agree,", "can't decide," "disagree," and "totally disagree." The scale content keeps parallelism with the theory of Whiteside and Lynam (2001): CU with urgency, II with lack of premeditation, and SS with sensation seeking.

The Cronbach alpha reliability indices of the instrument ranged from acceptable to very good (CU .73, SS .81, and II .85).

\section{Measure for risky/safe decision-making}

The Game of Dice Task (GDT, Brand, Heinze, Labudda, \& Markowitsch, 2008). was used to evaluate risky vs. safe decision-making. This computerized task enables the observation of the performance of subjects in a betting task that includes risky and safe options. This study uses the conceptualization of risk-taking by Gratz et al. (2014). The instrument consists of four options to win certain amounts of money by betting on the outcome of a dice roll (one of the dice faces). If the proposed number rolls, the individual gains fictional currency, but if there is a different outcome, the individual is punished by losing the same amount of money. The four types of bets range from riskier 
to safer bets. The different options are as follows: 1 ) choose a single face of the dice; 2) choose two faces; 3 ) choose 3 faces; and 4) choose four faces. Each choice is associated with fictional gains and losses: a $\$ 1000$ gain or loss for option 1 ; a $\$ 500$ gain or loss for option 2 ; a $\$ 200$ gain or loss for option 3 ; and a $\$ 100$ gain or loss for option 4 . Options 3 and 4 are considered safer because the probability of success increases, while options 1 and 2 are riskier because there's a higher probability to lose. The greater amount of money that can be won by taking higher risks makes options 1 and 2 more attractive, while the opposite is true for options 3 and 4 . A cube that appears on the screen randomly delivers results from a fictive dice after the bet was made by the participant. The number of risky choices ( 1 and 2) and safe choices (3 and 4) is recorded along with the money won, lost and the balance of losses and gains at the end of 30 game trials.

\section{Cognitive abilities measures}

Several neuropsychological tests were used to measure executive - attentional functioning. Processing speed, concentration, and different types of errors were evaluated using the $\mathrm{d} 2$ test (Brickenkamp, 2002). This test allows the identification of different problems arising from inattention and impulsivity. Different types of errors were considered: omission errors (e.g., not marking a correct stimulus) and commission errors (e.g., marking a distractor stimulus). To measure the inhibition of attentional interference (selective attention), the Stroop, or Colour and Word Test, was administered (Golden, 2007). In addition, the Trail Making Test (TMT), parts A and B, was used to measure processing speed and attentional alternation (AITB, 1944; Reitan \& Wolfson 1993). To evaluate the attentional amplitude and estimate working memory, one of the WAIS-III scales, direct and inverse digits amplitude, was applied (Wechsler, 2002). To measure the interviewee's fluency, two tests were administered: the speed in evocation of verbal material was estimated based on the semantic and phonological verbal fluency task (Goodglas \& Kaplan; 1996; Butman, Allegri, Harris, \& Drake, 2000); functioning non-verbal fluency was measured on the basis of performance on the fivepoint test (Ruff, 1996).

\section{Procedure and Data Analysis}

The design of the research is ex post facto because of the participants' characteristics that were used as predictors for the performance of the laboratory tests (León \& Montero, 2007).

As the homoscedasticity and normality criteria were not met in most cases, non-parametric inferential statistics were used (Pardo Merino \& San Martín Castellanos, 1998). However, because of their lower power to find significant differences where these could occur, these tests can be subject to demand for testing hypotheses at statistical levels (Hopkins \& Glass, 1997).

The association between the three proposed impulsivity factors and the different dependent variables was statistically evaluated through bivariate correlations. The Spearman's Rho statistic was used to find significant associations.

The medians of different measures for dependent variables were also compared in different participant groups who shared extreme scores in the three impulsivity subtypes. The subjects who ranked below the 25th percentile and above the 75th percentile of the sample were identified in each of the proposed factors: CU, SS, and II. The individuals with intermediate scores in each personality variable were not considered. The Mann-Whitney $U$ statistic for independent samples was applied to compare each subject's outcome, classified as high and low in each characteristic, on their performance in each test or evaluation on the self-report scale. To estimate the power of the comparison effect of low and high groups for the trait, Cliff's Delta Statistic (Romano, Kromrey, Coraggio, Skowronek, \& Devine, 2006) was used. This is a nonparametric statistic that allows calculation of the effect size measure that quantifies the amount of difference between two groups of observations. To consider the effect size, the criteria of Romano et al. (2006) (low = .15 ; medium $=.33$; high $=.47$ ) were used. The Cliff's Delta Calculator program was applied to estimate this statistic (Macbeth, Razumiejczyk \& Ledesma, 2011).

Once the factors that had significant effects on the studied variables were detected, they were again tested individually, while controlling for the other intervening factors. To identify which subtypes of impulsivity were related to each investigated area, simple binary logistic regressions were performed (Peng, Lee, \& Ingersoll, 2002). In this case, we aimed to control the effect of other factors that could function as confounding variables by subtracting the effect of the other impulsivity subtypes and controlling for the effects of age and years of schooling. Binomial logistic regression was chosen because it's a more robust method than linear regression or discriminant analysis. In logistic regression the dependent variable is not required to have a normal distribution, nor must assumptions be made about the predictor variables (Peng et al., 2002). To carry out this analysis, the subjects who ranked below the 25th percentile and above the 75th percentile of the sample were divided in each one of the neuropsychological dependent factors. Subjects ranked with intermediate scores were excluded. Correlations between independent variables in the model scored low (237 to 256), a fact that allowed their incorporation into the model (Franco, Gaviria, Torres \& Cotes, 2007). In order to include all impulsivity subtypes to the model, a backward procedure was applied and variables were 
progressively eliminated if necessary (if they did not make a significant contribution). The omnibus test was not significant, which indicates a good of fit and the possibility of using the output models

(Franco et al., 2007). To estimate the effect size, Nagelkerke $\mathrm{r}^{2}$, a modified version of Cox and Snell $\mathrm{r}^{2}$, (Bewick, Cheek, \& Ball, 2005) was applied. To classify the effect power, the Cohen criterion (1992) was used (low $=.10$, medium $=.30$, high $=.50$ ). In addition, the coefficient of determination $r^{2}$ was calculated to study the percentage of variance explained above.

Table 1

Correlations of impulsivity subtypes with risky vs. safe decision-making $(n=228)$

\begin{tabular}{lllll}
\hline & Game of Dice Task & Impulsivity Subtype & & \\
\hline \multirow{4}{*}{ Risky } & SS & CU & II \\
& Option 1 & $.206 * \star$ & .084 & $.177^{\star}$ \\
Safe & Option 2 & $.212^{\star \star}$ & .012 & .144 \\
& Option 3 & .002 & -.055 & -.039 \\
& Option 4 & $-.257 \star *$ & -.019 & -.115 \\
& Won & $.241 * \star$ & .105 & $-.169 *$ \\
& Lost & $.197 *$ & .064 & .109 \\
& Gain & $-.148 *$ & -.010 & -.029 \\
\hline
\end{tabular}

Note: $p<.05 ; * \star p<.01$, (bilateral significance)

The analysis based on the Mann-Whitney $U$ test indicated significant differences between subjects who scored low and high on SS in the DT decision-making. Participants who scored high on SS opted significantly more for options 1 and 2 (risky) than those who scored low on this trait $(\mathrm{Z}=-2.980, \mathrm{p}=.003)$ and $(\mathrm{Z}=-2.840$, $\mathrm{p}=.005)$, respectively. By contrast, those who scored high on SS opted significantly more for option 4 (safe) than those who scored lower on this facet $(Z=-2.711$, $\mathrm{p}=.007)$. Those scoring high on SS also made more money $(\mathrm{Z}=-3.180, \mathrm{p}=.001)$ and lost more money $(\mathrm{Z}$ $=-3.030, p=.002)(Z=-3.030, p=.002)$ during their

\section{Results}

\section{Decision-making}

Spearman's rho correlations indicated associations of the SS facet with several variables of the decisionmaking tests of the DT. This characteristic was significantly related to a higher selection of the riskiest options (options 1 and 2) and to a lower selection of the safest option (option 4). Likewise, SS was associated with both winning and losing more money, negatively affecting the total gain. The II facet showed two associations, one with the riskiest option (option 1) and another with the greatest money earned. Finally, the CU was not found to be associated with the performance in the DT (Table 1).

Table 2

Logistic regression models on the performance in the Game of Dice Task

\begin{tabular}{llllllllll}
\hline DV & IV & $\mathbf{n}$ & $\mathbf{B}$ & S.E. & Wald & df & $\boldsymbol{P}$ & OR & 95\% Cl -OR \\
\hline Option 1 & SS & 64 & 1.540 & .554 & 7.741 & 1 & .005 & 4.667 & {$[1.577-13.813]$} \\
Option2 & SS & 51 & 1.333 & .601 & 4.925 & 1 & .026 & 3.792 & {$[1.169-12.303]$} \\
Option 3 & - & - & - & - & - & - & - & - & - \\
Option 4 & SS & 50 & -1.115 & .593 & 3.534 & 1 & .060 & .328 & {$[.103-1.049]$} \\
Money Won & SS & 47 & 1.915 & .655 & 8.550 & 1 & .003 & 6.786 & {$[1.880-24.491]$} \\
Money Lost & SS & 48 & 1.966 & .653 & 9.070 & 1 & .003 & 7.143 & {$[1.987-25.678]$} \\
Gain & SS & 54 & -1.110 & .483 & 5.272 & 1 & .022 & .330 & {$[.128-.850]$} \\
\hline
\end{tabular}

Note. $\mathrm{DV}=$ dependent variable; IV = independent variable; S.E. = standard error; $\boldsymbol{d f}=$ degrees of freedom; $\mathrm{OR}=$ odds ratio; $\boldsymbol{p}<.05, \mathrm{bilateral}$ significance) 
The model indicated that SS accounted for between $12.2 \%$ and $16.6 \%$ of the variance of the selection of option 1, according to Cox Snell $r^{2}$ and Nagerlkerke $r^{2}$, respectively. Regarding option 2, SS predicted between $9.6 \%$ and $13 \%$ of the variance according to Cox Snell $r^{2}$ and Nagerlkerke $r^{2}$, respectively. As to option 4, SS generated a trend that accounted for between $7.1 \%$ and $9.5 \%$ of the variance, according to Cox Snell $r^{2}$ and Nagerlkerke $r^{2}$, respectively. The logistic regression model also showed that SS accounted for between $18.4 \%$ and $24.5 \%$ of the variance on the money made, according to Cox Snell $r^{2}$ and Nagerlkerke $r^{2}$, respectively. The SS also predicted between $19.1 \%$ and $25.5 \%$ of the variance of money lost, according to Cox Snell $r^{2}$ and Nagerlkerke $r^{2}$, respectively. Regarding the final earnings, SS explained between $7.1 \%$ and $9.5 \%$ of the variance, according to Cox Snell $r^{2}$ and Nagerlkerke $r^{2}$, respectively. Finally, the selection of option 3 was not predicted by any of the variables. When the effect size was analysed with Cliff's d, mean values were found (Appendix Table A).

\section{Executive - attentional functions}

When the different tasks that measure attention and executive functioning were evaluated, the three aspects of impulsivity were found to show significant associations. The features of CU and II were associated with the types of errors in the $\mathrm{d} 2$ test. The higher the $\mathrm{CU}$, the greater the number of omission and commission errors predicted, while the higher the II, only the greater number of commission errors were predicted. As for the Stroop test, the CU facet predicted an inverse relationship in performance in the Word-Colour (WC) sheet. Finally, higher scores on SS were associated with higher speed in the execution of both parts, A and B, of the TMT (Table 3).

Table 3

Correlations of Impulsivity Subtypes and d2 Test $(n=220)$

\begin{tabular}{|c|c|c|c|c|}
\hline & & \multicolumn{3}{|c|}{ Impulsivity Subtype } \\
\hline & & SS & II & $\mathrm{CU}$ \\
\hline \multicolumn{5}{|c|}{ d2 } \\
\hline TR & & .008 & -.071 & -.019 \\
\hline TCR & & .096 & -.012 & .044 \\
\hline 0 & & -.134 & .114 & $.277 \star \star$ \\
\hline C & & -.009 & $.208 *$ & $.232 \star \star$ \\
\hline \multicolumn{5}{|c|}{ TMT } \\
\hline TMT- A & & $-.195 *$ & .077 & .007 \\
\hline \multirow[t]{2}{*}{ TMT - B } & & $-.141 *$ & .006 & -.026 \\
\hline & Stroop & & & \\
\hline W & & .076 & -.098 & .042 \\
\hline C & & .088 & -.043 & -.131 \\
\hline WC & & .077 & -.025 & $-.216 * *$ \\
\hline$E$ & & -.001 & .022 & .023 \\
\hline
\end{tabular}

Note: $\mathrm{d} 2$ task: TR, total responses; TCR, total correct responses; O, omission errors; C, commission errors. TMT Task, Trail making Task, part A, part B. Stroop task: W, word list; C, color list; WC, word and color list; E, number of perseverative errors committed. * $p<.05 ; * \star p<$ .01 (bilateral significance).

The analysis based on the Mann-Whitney $\mathrm{U}$ test indicated significant differences between subjects scoring low and high on CU and II, in the types of errors committed in $\mathrm{d} 2$. Individuals scoring high on $\mathrm{CU}$ committed a higher number of omission errors $(\mathrm{Z}=$ $-3.689, \mathrm{p}<.000)$ and commission errors $(Z=-2.690$, $\mathrm{p}=.007)$ than those scoring low. On the other hand, individuals who scored high on II committed a higher number of commission errors $(\mathrm{Z}=-2.083, \mathrm{p}=.037$ ) than those who scored low.

The analysis based on the Mann-Whitney U test indicated significant differences between individuals scoring low and high on CU. Those scoring high on CU discriminated between fewer items on the WC list $(\mathrm{Z}=$ -2.399, $\mathrm{p}=.016$ ).

When the binary logistic regression models were applied, the CU facet was the only predictor of worse performance on two of the attentional variables evaluated. A higher CU predicted the increase in omission errors in the $\mathrm{d} 2$ and a lower ability to discriminate between items on the WC list of the Stroop test. In addition, SS was a positive predictor of shorter execution time for both parts, A and B, of the TMT test. The model discarded other features of impulsivity as well as the participant's age and years of schooling (Table 4). 
Table 4

Logistic regression models on the performance in the d2, Stroop, and TMT tasks

\begin{tabular}{llllllllll}
\hline DV & IV & $\mathbf{n}$ & B & S.E. & Wald & df & P & OR & 95\% Cl -OR \\
\hline Stroop - WC & CU & 130 & -.747 & .357 & 4.381 & 1 & .036 & .474 & {$[.235-.954]$} \\
d2 -O & CU & 176 & .684 & .315 & 4.710 & 1 & .030 & 1.981 & {$[1.069-3.673]$} \\
TMT-A & SS & 116 & -1.360 & .393 & 11.953 & 1 & .001 & .257 & {$[.119-.555]$} \\
TMT-B & SS & 118 & -.831 & .378 & 4.845 & 1 & .028 & .435 & {$[.208-.913]$} \\
\hline
\end{tabular}

Nota.Stroop WC $=$ third Word Color sheet of Stroop task. O = omission errors of d2 task.TMT Task, Trail making Task, part A, part B. $\mathrm{DV}=$ dependent variable; IV = independent variable; S.E. = standard error; $\boldsymbol{d f} f$ =degrees of freedom; OR= odds ratio; $p<.05$, (bilateral significance).

The model indicated that CU accounted for between $3.4 \%$ and $4.5 \%$ of the variance of the execution on the Word-Colour list of the Stroop test, according to Cox Snell r2 and Nagerlkerke r2, respectively. Likewise, CU predicted between $3.0 \%$ and $3.6 \%$ of the variance on the occurrence of omission errors in the $\mathrm{d} 2$ task. When the effect size was analysed with Cliff's d, mean values were found (Appendix Table B).

Furthermore, SS accounted for between 10.3\% and $13.8 \%$ of the variance in the speed of execution of the TMT, part A, and between $4.1 \%$ and $5.5 \%$ of the variance in time of execution for part $\mathrm{B}$. When the effect size was analysed with Cliff's d, median's values were to be found (Appendix Table C).

\section{Verbal and non-verbal fluency}

In the fluency tasks, the II facet was related to the nonverbal task of the 5-point test. The II scale predicted a greater number of designs but also a higher number of errors due to repetition. On the other hand, it indicated a positive association with a greater number of words uttered in the phonological fluency test. The CU facet showed no association with performance in the fluency tests (Table 5).

Table 5.

Correlations of impulsivity subtypes with verbal and non-verbal fluency test $(n=215)$

\begin{tabular}{llll}
\hline FluencyTask & Impulsivity Subtype & & \\
\hline \multicolumn{1}{c}{ Verbal } & SS & CU & II \\
Phonological fluency & $.173^{*}$ & -.124 & -.029 \\
Semantic Fluency & .110 & -.114 & .004 \\
$\quad$ Non-verbal & & & $.209 * \star$ \\
Five-point test & .115 & -.053 & $.181_{\star \star}$ \\
Perseverative errors & .164 & -.020 & \\
\hline
\end{tabular}

Note: $* p<.05 ; * * p<.01$.

The analysis based on the Mann-Whitney U test indicated a significant tendency in individuals scoring high on SS towards a greater number of words in the phonological fluency task $(\mathrm{Z}=-1.931, \mathrm{p}=.053)$ than those who scored low on this facet. On the other hand, participants scoring high on II both made significantly more designs in the five-point test than low scorers $(\mathrm{Z}=-2.976, \mathrm{p}=.003)$, and also performed a greater number of repetitions in the designs (perseverance) $(\mathrm{Z}$ $=-2.747, \mathrm{p}=.006)$. When binary logistic regression models were applied to the performance in the $\mathrm{d} 2$ and 5 -point tests, significant predictions of II were found (Table 6).

Table 6.

Logistic regression models of the performance in the phonological fluency test and the 5-point test

\begin{tabular}{llllllllll}
\hline DV & VI & $\mathbf{n}$ & B & E.E. & Wald & df & P & OR & 95\% CI - OR \\
\hline Fluency -Ph & SS & 76 & 1.258 & .491 & 6.571 & 1 & .010 & 3.518 & {$[1.345-9.203]$} \\
5-point -D & II & 97 & 1.270 & .435 & 8.516 & 1 & .004 & 3.560 & {$[1.517-8.354]$} \\
5-point - P & II & 148 & 1.014 & .367 & 7.621 & 1 & .006 & 2.756 & {$[1.342-5.659]$} \\
\hline
\end{tabular}

Note. Fluency - Ph, phonological fluency task; 5-point-D, number of designs on the 5-point test; 5-point-P, five-point test, number of perseverative errors. DV = dependent variable; IV = independent variable; S.E. = standard error; $d f=$ degrees of freedom; OR= odds ratio; $p$ $<.05$, (bilateral significance) 
The SS model accounted for between $8.7 \%$ and $11.7 \%$ of thevariance on the performance in phonological fluency, according to Cox Snell $r^{2}$ and Nagerlkerke $r^{2}$, respectively. In addition, the II facet accounted for between $8.9 \%$ and $11.9 \%$ of the variance on the number of designs made in the 5-point test, according to Cox Snell $r^{2}$ and Nagerlkerke $r^{2}$, respectively. Finally, II predicted between $5.2 \%$ and $7.3 \%$ of the variance on the performance of perseverative errors on the fivepoint test according to Cox Snell $r^{2}$ and Nagerlkerke $r^{2}$, respectively. When the effect size was analysed with Cliff's d, mean values were found (Appendix Table D).

\section{Discussion}

The controls conducted with logistic regressions revealed three distinctive profiles for impulsivity subtypes on executive-attentional skills and decisionmaking. As previously suggested, the best predictor of risky behaviour and disadvantageous decisionmaking was the lack of premeditation facet of the UPPS model. Bechara and Van der Linder (2005) argued that this facet was associated with risky strategies in the IGT. It was this impulsivity subtype that attracted attention as the predictive factor of poor planning for decision-making. However, subsequent research did not confirm such a relationship (Bayard et al., 2011). In this study, the II construct is equivalent in content to lack of premeditation (Squillace \& Picón Janeiro, 2017). The II construct was found to be associated with the selection of a riskier option and reduction in gains. However, when other intervening factors were controlled for SS was found to be the best predictor of these variables. The II facet was, in fact, able to predict a bad strategy in the performance of non-verbal fluency, which caused greater errors due to a tendency towards perseveration. The five-point test is associated with the functioning of right frontal regions (Fernández, Moroni, Carranza, Fabbro, \& Lebowitz, 2009; Lee et al., 1997). The inconsistencies in the previous findings on the II (Rochat et al., 2018) could have been due to not previously finding effects for the laterality of brain functioning on impulsivity. Further testing is needed to estimate right hemispheric functioning.

Moreover, the CU predicts a profile different from that of II. On the one hand, it is the facet that has been most associated with difficulties in the executive control of attention. When the other intervening variables were controlled for, a high CU predicted greater failure due to greater commission errors and greater interference during the Stroop task. These findings are consistent with previous research (Billieux et al., 2010; Rochat et al., 2018) and could mean that this personality trait is caused by the alteration of executive-attentional mechanisms. Such cognitive difficulties would be responsible for a high variety of psychopathological problems of impulse control (Berg et al., 2015; Billieux et al., 2007; Tabibnia et al., 2011). Unlike the findings on dimension II, the failure occurred in the tests related to the functioning of the left hemisphere, such as the Stroop task (Zhang, Sun, Sun, Luo, \& Gong, 2014) as well as the $\mathrm{d} 2$ task, related to left-right interhemispheric integration (Budde, Voelcker-Rehage, PietraßykKendziorra, Ribeiro, \& Tidow, 2008).

Finally, high SS was related to efficient performance in the executive-attentional tasks, verbal fluency, and speed of information processing with respect to its low counterpart. The observed behaviour is associated with the concept of functional impulsivity (FI) initially proposed by Dickman (1990). The FI refers to acting quickly and accurately, with a calculated risk that contributes to achieving a goal quickly and effectively. To this effect, Chico (2000) describes individuals who behave meticulously to achieve sufficient safety so as not to fail in their search for excitement. Previous research also shows that FI is related to a better performance in neuropsychological tasks, as measured by Dickman's theory (Pedrero-Pérez, Ruiz Sánchez de León, Rojo Mota, Llanero Luque, \& Puerta García, 2012).

However, when subjects scoring high in SS are exposed to reward signals, such as the high gains that could be obtained by opting for risky instead of safe decisions, they end up selecting a disadvantageous strategy in the DT. Despite their better cognitive abilities, their high sensitivity to rewards leads these individuals to take risks and lose the game (negative gains), as opposed to those scoring low on this facet.

\section{Conclusion}

In the present article, we concluded that good cognitive functioning associated with SS, together with its high sensitivity to rewards, could make the subjects feel safe enough to take risks that lead to greater excitement. However, their high sensitivity to rewards does not allow them to realize that the result turns out to be disadvantageous if they lose more money than they win.

Furthermore, it is interesting to note how the work of disentangling the concept of impulsivity leads to a hybrid area between the field of personality and that of basic processes such as attention and executive functions. The former field of study has always been associated with the individual's style and the latter with their capacities and abilities, two territories usually seen as independent areas with supposedly unrelated subject matters. As regards the latter, we found that CU was related to a low attentional performance when we used tests that measured mostly the functioning of the executive abilities of the left hemisphere. On the other 
hand, we observed that II was related to difficulties in the executive control of the fluency of non-verbal information processing, linked to difficulties that may be related to alterations in the functioning of the right frontal regions. Finally, the SS indicated a very good performance in executive-attentional control, verbal fluency, and speed of information processing. This cognitive efficiency was possibly related to the subjects' tendency to take more risks than other individuals. Further studies are necessary to see the consistency of these findings in new samples and populations. For example, it would be necessary to find greater evidence discriminating between cerebral hemispheric functioning to verify the differences found between II and CU. Further decision-making tests are also needed to verify the phenomenon of risk-taking in the SS.

\section{References}

Bayard, S., Raffard, S., \& Gely-Nargeot, M. C. (2011). Do facets of self-reported impulsivity predict decision-making under ambiguity and risk? Evidence from a community sample. Psychiatry Research, 190(2-3), 322-326. doi:10.1016/j. psychres.2011.06.013

Bechara, A., \& Van Der Linden, M. (2005). Decision-making and impulse control after frontal lobe injuries. Current opinion in neurology, 18(6), 734-739. doi:10.1097/01. wco.0000194141.56429.3c

Berg, J. M., Latzman, R. D., Bliwise, N. G., \& Lilienfeld, S. O. (2015). Parsing the heterogeneity of impulsivity: A meta-analytic review of the behavioral implications of the UPPS for psychopathology. Psychological Assessment, 27(4), 1129-1146. doi:10.1037/ pas0000111

Bewick, V., Cheek, L., \& Ball, J. (2005). Statistics review 14: Logistic regression. Critical Care, 9(1), 112118. doi :10.1186/cc3045

Billieux, J., Gay, P., Rochat, L., \& Van der Linden, M. (2010). The role of urgency and its underlying psychological mechanisms in problematic behaviours. Behaviour research and therapy, 48(11), 1085-1096. doi:10.1016/j. brat.2010.07.008

Billieux, J., Rochat, L., Rebetez, M. M. L., \& Van der Linden, M. (2008). Are all facets of impulsivity related to self-reported compulsive buying behavior?. Personality and Individual Differences, 44(6), 1432-1442. doi:10.1016/j. paid.2007.12.011

Billieux, J., Van der Linden, M., \& Ceschi, G. (2007). Which dimensions of impulsivity are related to cigarette craving?. Addictive behaviors, 32(6), 1189-1199. doi:10.1016/j.addbeh.2006.08.007
Brand, M., Heinze, K., Labudda, K., \& Markowitsch, H. J. (2008). The role of strategies in deciding advantageously in ambiguous and risky situations. Cognitive Processing, 9(3), 159-173. doi:10.1007/s10339-008-0204-4

Brickenkamp, R. (2002). D2, Test de atención (trans. Spanish N. Seisdedos). Madrid: TEA Ediciones.

Budde, H., Voelcker-Rehage, C., Pietraßyk-Kendziorra, S., Ribeiro, P., \& Tidow, G. (2008). Acute coordinative exercise improves attentional performance in adolescents. Neuroscience letters, $441(2), \quad 219-223 . \quad$ doi:10.1016/j. neulet.2008.06.024

Butman, J., Allegri, R., Harris, P. \& Drake, M. (2000). Fluencia verbal en español datos normativos en Argentina. Medicina, Buenos Aires, 60, 561-564.

Chico, E. (2000). Relación entre la impulsividad funcional y disfuncional y los rasgos de personalidad de Eysenck. Anuario de Psicología, $31(1), 79-87$.

Costa Jr, P. T., \& McCrae, R. R. (1995). Domains and facets: Hierarchical personality assessment using the Revised NEO Personality Inventory. Journal of Personality Assessment, 64(1), 21-50. doi:10.1207/s15327752jpa6401_2

Cyders, M. A., \& Coskunpinar, A. (2011). Measurement of constructs using self-report and behavioral lab tasks: Is there overlap in nomothetic span and construct representation for impulsivity?. Clinical Psychology Review, 31(6), 965-982. doi:10.1016/j.cpr.2011.06.001

Cyders, M. A., \& Smith, G. T. (2008). Clarifying the role of personality dispositions in risk for increased gambling behavior. Personality and Individual Differences, 45(6), 503-508. doi:10.1016/j. paid.2008.06.002

Cyders, M. A., \& Smith, G. T. (2007). Mood-based rash action and its components: Positive and negative urgency. Personality and Individual Differences, 43(4), 839-850. doi:10.1016/j.paid.2007.02.008

Dickman, S. J. (1990). Functional and dysfunctional impulsivity: personality and cognitive correlates. Journal of personality and social psychology, 58(1), 95-102. doi:10.1037/0022-3514.58.1.95

Fernández, A. L., Moroni, M. A. Carranza, J. M., Fabbro, N., \& Lebowitz, B. K. (2009). Reliability of the FivePoint Test. The Clinical Neuropsychologist, 23(3), 501-509. doi:10.1080/13854040802279675

Franco, J. G., Gaviria, A. M., Torres, Y., \& Cotes, J. M. (2007). Regresión logística en la literatura psiquiátrica: evaluación de los artículos publicados entre 2002 y 2005 en una prominente revista. Revista Brasileira de Epidemiología, 10(3), 370-379. 
Gay, P., Courvoisier, D. S., Billieux, J., Rochat, L., Schmidt, R. E., \& Van der Linden, M. (2010). Can the distinction between intentional and unintentional interference control help differentiate varieties of impulsivity? Journal of Research in Personality, 44, 46-52. doi:10.1016/j. jrp.2009.10.003

Gay, P., Rochat, L., Billieux, J., d'Acremont, M., \& Van der Linden, M. (2008). Heterogeneous inhibition processes involved in different facets of self-reported impulsivity: Evidence from a community sample. Acta Psychologica, 129(3), 332-339. doi:10.1016/j.actpsy.2008.08.010

Golden, C. J. (2007). Stroop test (5th Ed.). Madrid, España: TEA Ediciones.

Goodglass, H., \& Kaplan, E. (1996). Evaluation of Aphasia and similar disorders (2nd. Ed.) Buenos Aires, Argentina: Panamericana.

Gratz, K. L., Kiel, E. J., Latzman, R. D., Elkin, T. D., Moore, S. A., \& Tull, M. T. (2014). Emotion: Empirical contribution: Maternal borderline personality pathology and infant emotion regulation: Examining the influence of maternal emotionrelated difficulties and infant attachment. Journal of Personality Disorders, 28(1), 52-69. doi:10.1521/pedi.2014.28.1.52

Herman, A. M., Critchley, H. D., \& Duka, T. (2018). Risktaking and impulsivity; the role of mood states and interoception. Frontiers in psychology, 9, 1625. doi:10.3389/fpsyg.2018.01625

Hopkins, K. D., \& Glass, G. V. (1997). Basic stadistics for social and behavioral science (3th. Ed.). Naucalpan de Juárez, México: Prentice Hall Hipanoaméricana, S. A.

Lee, G. P., Strauss, E., Loring, D. W., McCloskey, L., Haworth, J. M., \& Lehman, R.A. W. (1997). Sensitivity of figural fluency on the fivepoint test to focal neurological dysfunction. The Clinical neuropsychologist, 11(1), 59-68. doi:10.1080/13854049708407030

León, O. G., \& Montero, I.. (2007). Research methods inpsychology and education (4th Ed.). McGrawHill/Interamericana de España.

López, R., Dauvilliers, Y., Jaussent, I., Billieux, J., \& Bayard, S. (2015). A multidimensional approach of impulsivity in adult attention deficit hyperactivity disorder.Psychiatry Research, 227(2-3), 290-295. doi:10.1016/j. psychres.2015.03.023

Macbeth, G., Razumiejczyk, E., \& Ledesma, R. D. (2011). Cliff's Delta Calculator: A non-parametric effect size program for two groups of observations. UniversitasPsychologica, 10(2), 545 - 555. Recovered from http://ref.scielo.org/jqfmjp
Pardo Merino, A., \& San Martín Castellanos, R. (1998). Data analysis in psychology II. (2nd ed.). Madrid: Ediciones Pirámide, S.A.

Pedrero-Pérez, E. J., Ruiz Sánchez de León, J. M., Rojo Mota, G., Llanero Luque, M., \& Puerta García C. (2012). Caracterización neuropsicológica de la impulsividad funcional y disfuncional en adictos a sustancias: implicaciones clínicas. Adicciones, 24(1), 51-58. doi:10.20882/adicciones.117

Peng, C. Y. J., Lee, K. L., \& Ingersoll, G. M. (2002). An introduction to logistic regression analysis and reporting. The Journal of Educational Research, 96(1), 3-14. doi:10.1080/00220670209598786

Ray, J. V., Poythress, N. G., Weir, J. M., \& Rickelm, A. (2009). Relationships between psychopathy and impulsivity in the domain of self-reported personality features. Personality and Individual Differences, 46(2), 83-87. doi:10.1016/j. paid.2008.09.005

Reitan, R. M., \&. Wolfson, D (1993). The Halstead-Reitan neuropsychological test battery: Theory and clinical interpretation (2nd ed.), Neuropsychology Press, Tucson, AZ

Rochat, L., Billieux, J., Gagnon, J. \& Van der Linden, M. (2018).A multifactorial and integrative approach to impulsivity in neuropsychology: insights from the UPPS model of impulsivity, Journal of Clinical and Experimental Neuropsychology, 40(1),45-61. doi:10.1080/13803395.2017.1313393

Romano, J., Kromrey, J. D., Coraggio, J., Skowronek, J., \& Devine, L. (2006). Exploring methods for evaluating group differences on the NSSE and other surveys: Are the t-test and Cohen'sd indices the most appropriate choices. In annual meeting of the Southern Association for Institutional Research (pp. 1-51).

Roley, M. E., Contractor, A. A., Weiss, N. H., Armour, C., \& Elhai, J. D. (2017). Impulsivity facets' predictive relations with DSM-5 PTSD symptom clusters. Psychological Trauma: Theory, Research, Practice, and Policy, 9(1), 76-79. doi:10.1037/2Ftra0000146

Rømer Thomsen, K., Callesen, M. B., Hesse, M., Kvamme, T. L., Pedersen, M. M., Pedersen, M. U., \& Voon, V. (2018). Impulsivity traits and addiction-related behaviors in youth. Journal of behavioral addictions, 7(2), 317-330. doi:10.1556/2006.7.2018.22

Ruff, R. M. (1996). Ruff Figural Fluency Test. Professional Manual. U.S.A: Psychological Assesment Resources, Inc.

Squillace Louhau, M., \& Picón Janeiro, J. (2019). CUBI18 un instrumento para medir tres subtipos de Impulsividad. Interdisciplinaria, 36(1) in press. 
Squillace, M., \& Picón Janeiro, J. (2017). La impulsividad es un constructo multifacético: validación del CUBI. Revista Evaluar, 17(1), 0117. Recovered from https://revistas.unc.edu.ar/ index.php/revaluar

Squillace, M., Picón Janeiro, J., \& Schmidt, V. (2011). El concepto de Impulsividad y su ubicación en las teorías psicobiológicas de la personalidad. Revista de Neuropsicología Latinoamericana 3(1), 8-18. doi:10.5579/rnl.2011.0057

Stanford, M. S., Mathias, C. W., Dougherty, D. M., Lake, S. L., Anderson, N. E., \& Patton, J. H. (2009). Fifty years of the Barratt Impulsiveness Scale: An update and review. Personality and Individual Differences, 47(5), 385-395. doi:10.1016/j. paid.2009.04.008

Tabibnia, G., Monterosso, J. R., Baicy, K., Aron, A. R., Poldrack, R. A., Chakrapani, S., ... \& London, E. D. (2011). Different forms of self-control share a neurocognitive substrate. Journal of Neuroscience, 31(13), 4805-4810. doi:10.1523/ JNEUROSCI.2859-10.2011

Um, M., Hershberger, A. R., Whitt, Z. T., \& Cyders, M. A. (2018). Recommendations for applying a multidimensional model of impulsive personality to diagnosis and treatment. Borderline personality disorder and emotion dysregulation, 5(1), 6. doi:10.1186/s40479-018-0084-x

Wechsler, D. (2002). WAIS-III, Intelligent scale. Buenos Aires, Argentina: Paidós.

Wilbertz, T., Deserno, L., Horstmann, A., Neumann, J., Villringer, A., Heinze, H. J., ... \& Schlagenhauf, F. (2014). Response inhibition and its relation to multidimensional impulsivity. Neuroimage, 103, 241-248. doi:10.1016/j.neuroimage.2014.09.021

Whiteside, S. P., \& Lynam, D. R. (2001). The five factor model and impulsivity: Using a structural model of personality to understand impulsivity. Personality and Individual Differences, 30(4), 669-689. doi:10.1016/S0191-8869(00)00064-7

Whiteside, S. P., Lynam, D. R., Miller, J. D., \& Reynolds, S. K. (2005). Validation of the UPPS Impulsive Behavior Scale: A four-factor model of impulsivity. European Journal of Personality, 19(7), 559-574. doi:10.1002/per.556

Zhang, L., Sun, J., Sun, B., Luo, Q., \& Gong, H. (2014). Studying hemispheric lateralization during a Stroop task through near-infrared spectroscopybased connectivity. Journal of Biomedical Optics, 19(5), 1-7. doi:10.1117/1.JBO.19.5.057012 


\section{Appendix}

Table A

Effect size of SS on decision-making

\begin{tabular}{llll}
\hline & 25th Percentile $(\mathbf{n})$ & 75th Percentile $(\mathrm{n})$ & Cliff's Delta \\
\hline Option 1 & 53 & 48 & $\mathrm{D}=-.3242$ \\
Option 2 & 53 & 49 & $\mathrm{D}=-.2891$ \\
Option 4 & 52 & 47 & $\mathrm{D}=.3367$ \\
Money won & 53 & 47 & $\mathrm{D}=-.3227$ \\
Money lost & 53 & 47 & $\mathrm{D}=-.3865$ \\
Gain & 52 & 47 & $\mathrm{D}=.2743$ \\
\hline
\end{tabular}

Table B

Effect size of $C U$ on executive-attentional tests

\begin{tabular}{llll}
\hline & 25th Percentile (n) & 75th Percentile (n) & Cliff's d \\
\hline Stroop WC & 57 & 67 & $\mathrm{D}=.2042$ \\
CU on O of d2 & 55 & 70 & $\mathrm{D}=-.1953$ \\
\hline
\end{tabular}

Note: Stroop WC $=$ third Word Color sheet of Stroop task. $\mathrm{O}=$ omission errors of $\mathrm{d} 2$ task.

Table C

Effect size of SS on executive-attentional tests

\begin{tabular}{llll}
\hline & 25th Percentile $(\mathrm{n})$ & 75th Percentile $(\mathrm{n})$ & Cliff's Delta \\
\hline TMT A & 58 & 61 & $\mathrm{D}=.2849$ \\
TMT B & 59 & 60 & $\mathrm{D}=.1997$ \\
\hline
\end{tabular}

Note: TMT $=$ Trail Making Test, part A and part B

Table D

Effect size of II and SS on verbal and non-verbal fluency tests.

\begin{tabular}{llll}
\hline & 25th Percentile (n) & 75th Percentile $(\mathrm{n})$ & Cliff's Delta \\
\hline II - D five-point test & 79 & 68 & $\mathrm{D}=.2848$ \\
II- P five-point test & 79 & 66 & $\mathrm{D}=.1969$ \\
SS - Phonological fluency & 55 & 59 & $\mathrm{D}=-.2092$ \\
\hline
\end{tabular}

Note: $\mathrm{D}=$ number of designs on the 5-point test. $\mathrm{P}=$ perseverative errors on the 5 -point test. 